\title{
A CONCEPTUAL FRAMEWORK FOR EFFECTIVE TUTORS AND TUTORING WITHIN A BLENDED LEARNING CONTEXT
}

\author{
Andrew Youde \\ University of Huddersfield (UNITED KINGDOM)
}

\begin{abstract}
This paper reports the findings of research that explored the practices of tutors in blended learning contexts. It investigated the skills, qualities and competences, particularly emotional competences, contributing to tutor effectiveness with the exploration including analysis of learners' perceptions of their quality. The research was undertaken on vocationally relevant degree courses for part-time learners. A mixed methods approach was adopted to conduct a detailed study of eight tutors' practice with data gathered from three principal sources. Interviews with tutors explored their approaches to delivery and considered factors that impacted on quality; students' perceptions of their learning experiences were assessed using an attitude survey; an analysis of the content and communications in the virtual learning environment provided insight into tutors' online practice. The research is based at a 'post 1992' university in the north of England and within an education disciplinary area. A conceptual framework is proposed for understanding the data generated in the form of a model of the observed tutor beliefs and practices. This represents an interpretation of effective practice in a particular cultural context and this framework may also be useful in understanding other instances of blended learning. The Model has three dimensions, which represent higher order 'concepts' - constructivism, care/nurture and instrumentality, together with 'lower level' factors, which are provided to operationalise the three broad conceptual areas. Further, the model suggests qualities and skills of effective tutors and tutoring in the context under investigation, which could support lecturers, course leaders and managers in delivering successful blended learning programmes.
\end{abstract}

Keywords: blended learning, adult learning, emotional competences, constructivism.

\section{INTRODUCTION}

This paper reports the findings of research that explored the practices of tutors in blended learning contexts. It investigated the skills, qualities and competences, particularly emotional competences (ECs), contributing to tutor effectiveness with the exploration including analysis of learners' perceptions of their quality. The research conducted a detailed study of eight tutors' teaching, learning, assessment and learner support on one of their modules, which formed approximately $6 \%$ of a learner's degree. The learners were undertaking part-time (PT), vocationally relevant degrees whilst, usually, in full-time (FT) employment. The principal aims of the research study were:

- to explore effective practice of tutors in blended learning environments

- to investigate skills, qualities and competences, particularly emotional competences, contributing to the effectiveness of tutors within blended learning environments

- to evaluate tutors' skills, qualities and competences through analysis of learners' perceptions

- to propose a model of the observed tutor beliefs and practices in blended learning environments.

The study proposes a conceptual framework for understanding the data generated in the form of a model of the observed tutor beliefs and practices. This represents an interpretation of effective practice in a particular cultural context and this framework may also be useful in understanding other instances of blended learning. Some findings and analysis of this research study have already been reported [1, 2 , 3], and are outlined further within this paper, with these contributing to the Model.

\section{RESEARCH CONTEXT}

This context has previously been described in conferences papers $[1,4,5,6]$. The research is based at a 'post 1992' university in the north of England which has approximately 520 full-time academic staff and 19,000 students. Blended learning delivery models were used on each course investigated and all were located within an education disciplinary area. The courses adopted a day school model of delivery 
where learners typically attend classes one day per month with the remaining time spent studying independently, utilising resources held on the virtual learning environment (VLE). Modules are usually a term in length (approximately three to four months) from the first day school until learners submit summative assessments. Tutors then have three weeks in which to mark their assignments and feedback. Each module, therefore, has two or three day schools with the overall course structure and delivery models developed by tutors and course leaders in conjunction with course approval committees. During a module, tutors have responsibility for teaching, assessment and monitoring learner progress. They are required to prepare suitable learning materials for both online contexts and day schools. Module syllabi and assessments, again, are developed by tutors and course leaders in conjunction with course approval committees. This includes both summative assessments and one opportunity for learners to receive feedback on a piece of formative assessment per module. Beyond this, tutors have autonomy in a number of aspects of teaching and learning. Day school content and teaching methods are solely within the control of the tutor who can structure delivery as they choose. Any further learning activities within a module, including online learning, are designed by module tutors and used at their discretion.

\section{METHODOLOGY}

An explanatory mixed methods design [7, p. 71] was adopted to conduct a detailed exploration of eight tutors' practice on one module delivered as part of a blended learning course. This firstly involved issuing a questionnaire to ascertain learners' perceptions of tutors, and the teaching, learning and assessment they experienced whilst studying the module. Qualitative analysis followed, via tutor interviews and VLE content analysis, which explored approaches to teaching and learning appearing to influence learner perceptions. The tutor sampling criteria applied were:

- they delivered the module on a 'day school' basis, that is, where learners attend university for a small number of days (typically two or three), with remaining teaching conducted via computer mediated communications (CMCs)

- they were an experienced teacher/lecturer (over five years) and had delivered at least three previous modules in blended learning contexts

- their learners were studying undergraduate or post-graduate courses on a part-time basis

- their learners were studying qualifications relevant to their profession.

A random selection of students ( $n=72$ covering the eight modules investigated) completed the questionnaire, which was designed to elicit general opinion about the quality of tutoring they experienced. To obtain this, a modified version of the Course Experience Questionnaire (CEQ) was used [8]. The scale items adopted were good teaching communication; good teaching feedback on, and concern for, student learning; clear goals and standards; and appropriate workload. Descriptive statistics generated from the questionnaire provided a broad overview of learner perceptions and a ranking of tutors, which then allowed the qualitative data to explain and build upon the initial quantitative results.

Qualitative data was gathered from interviews with tutors, which explored their approaches to delivery and considered factors that impacted on quality, and an analysis of the content and communications in the VLE, which provided insight into their online practice. Template analysis was chosen to analyse both the tutor interview data and VLE communications [9]. King [9, p. 256] argues that template analysis is not a single method or research itself, or a methodological position, but a series of techniques for the inductive analysis of textual data. The first template had a mix of descriptive codes, such as tutor experience, and analytical codes, for example, tutor ability to work within available resources. Flexibility was required in template development and subsequent analysis, particularly as themes were developing around tutor perceptions and beliefs appearing to align with learner feedback. Themes were noted as the coding process was undertaken and were analysed using a framework approach to thematic analysis [10, p. 550], which involved tabulating emerging ideas against tutors (who were ranked in descending order of learner perceptions, as measured by CEQ scores). Through this process, themes emerged that were important in all modules; important in those of tutors receiving the highest CEQ scores; and those that were only observable in the tutors receiving lower scores. 


\section{THE MODEL OF THE OBSERVED TUTOR BELIEFS AND PRACTICES}

The study's aims identified the issues to be explored within this research study, which included effective practice in teaching, learning, assessment and learner support, as well as considering other issues that influence learner perceptions of quality in the context under investigation. Stronge [11, p. 64] stated that "teaching effectiveness draws on a multitude of skills and attributes in different combinations and in different contexts to produce the results that define effectiveness", and this was certainly apparent in this research as a complex, multi-dimensional nature of effective teaching emerged. However, a clear conceptualisation of effective practice is proposed, which is supported by a summary of tutor qualities and competences. This paper now develops the Model of the Observed Tutor Beliefs and Practices in the context under investigation (see Figure 1). The Model has three dimensions, which include higher order 'concepts' - constructivism, care/nurture and instrumentality, together with 'lower level' factors, which are provided to operationalise the three broad conceptual areas. The first dimension, Constructivism, represents students' learning as achieving understanding. The second dimension, Care/Nurture, represents the support, and nature of that support, provided by tutors for their learners. The third dimension, Instrumentality, represents other factors beyond constructivism and care/nurture that contribute to the effectiveness of tutors within blended learning contexts. The Model is a conceptual framework for understanding the data generated from the practices of eight tutors and their approach to delivery of a module within a higher education (HE) institution. This represents an interpretation of effective practice in a particular cultural context and this framework may be useful in understanding other instances of blended learning in similar contexts. The Model suggests qualities and skills of effective tutors and provides a summary of effective tutoring in the context under investigation, which could support tutors, course leaders and managers in delivering successful blended learning programmes.

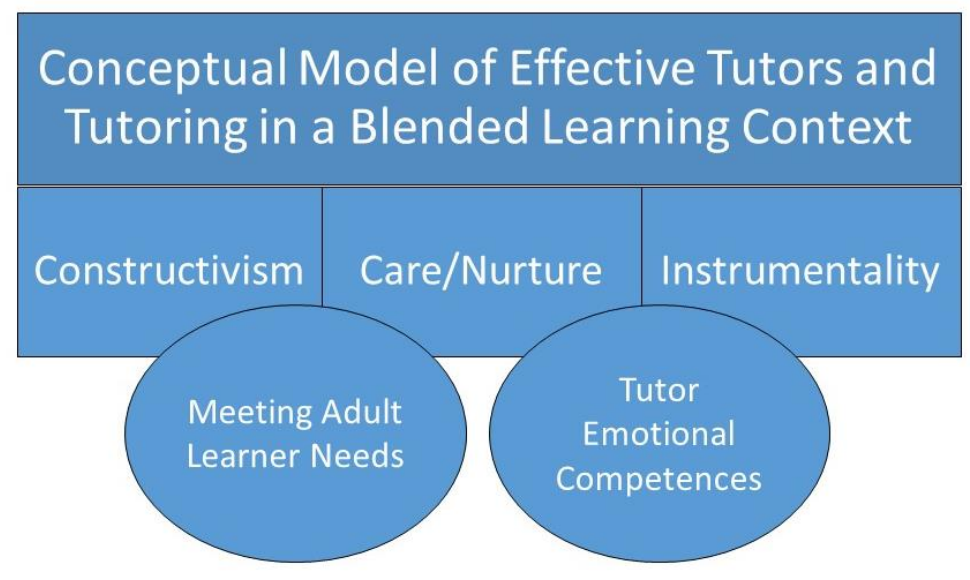

Figure 1 A Model of the Observed Tutor Beliefs and Practices

The Model is supported by the group of ECs [2] and assumes effective tutors possess these competences. These ECs predominantly support the Care/Nurture Dimension, such as the example of tutors being committed to learner support, but also aspects of Instrumentality, such as tutors manage competing pressures and are organised. The Model is further supported by the proposed Andragogical Model [3] for blended learning contexts and the factors it contained to operationalise its core principles. These factors predominantly support the Constructivism Dimension, but also elements of Care/Nurture. Elements of practice that informed the Model's development are now discussed with the lower level factors summarised in the next section.

\section{THE OPERATIONALISATION OF THE MODEL OF OBSERVED TUTOR BELIEFS AND PRACTICES}

This section now presents 'lower level' factors, which are provided to potentially guide blended learning practitioners, course leaders and university departments in similar contexts. These factors help operationalise the three broad conceptual areas of effective blended tutors and tutoring.

The Model firstly proposes factors present across all modules that were associated with their general success. This paper argues that these factors do not all have to be present for a successful blended 
learning experience, but are certainly associated with effective practice. Some factors could be missing, but particularly with the intrinsically motivated learners found in the research [3], the modules would still be generally considered successful. For example, the Model highlights robust technical support as a factor associated with general success as all tutors mentioned this was apparent when delivering modules. However, as there were no issues with technical support on the modules under investigation, it is difficult to confidently state it is essential for successful module outcomes. One tutor's module, heavily disrupted by external events, still had learners achieving and generally happy with their learning experience. Secondly, the Model proposes factors influencing learner perceptions of quality established from this research study. These factors are highlighted from effective tutors, namely those receiving higher CEQ scores, and indicate practices that if not present or exhibited, would influence learner perceptions of quality.

For ease of presentation, the lower level factors are outlined in three tables that describe:

- Constructivism (Table 1) [1]

- Care/Nurture (Table 2) [2]

- Instrumentality (Table 3).

Below each is a brief discussion and rationale of the dimension's content. The underpinning research for this paper [2] found tutor practices showed congruence with Mayes and de Freitas's Individual Constructivist Perspective (ICP) [12], a model of aligned practices within blended learning environments. It has roots in Biggs' notion of constructive alignment [13]. This ICP highlights the achievement of understanding through active discovery where learners construct new ideas by hypothesis testing [12]. The pedagogy aligning with this perspective includes interactive environments for knowledge expansion, cognitive scaffolding, experimentation with the discovery of principles, adaptation of teaching to existing student understanding, and support for reflection, analysis and evaluation. Assessment strategies aligning with this perspective encourage experiential learning, experimental learning, problem-based learning, case-based learning and self-evaluation, and autonomy in learning. When considering tutor practices as part of the research I considered this perspective primarily focused on students generally learning independently from tutors and peers. However, tutors provide support to learners, engage in dialogue regarding learning and assessment, but with limited peer interaction and collaboration occurring outside face-to-face contexts. (See Youde [2] for a more detailed description of how the research findings aligned with the ICP and why this approach was appropriate for adult learners in this context).

Table 1 Constructivism Dimension's lower level factors

\begin{tabular}{|l|l|l|}
\hline & $\begin{array}{l}\text { Constructivism - factors associated with, and influencing, learner perceptions of } \\
\text { quality }\end{array}$ \\
\hline Factors & $\begin{array}{l}\text { The Individual Constructivist Perspective [12] was the predominant } \\
\text { approach to module teaching, learning and assessment }\end{array}$ \\
effective & $\begin{array}{l}\text { A facilitative teaching style was the predominant approach } \\
\text { practice }\end{array}$ & $\begin{array}{l}\text { Assessments were problem-based } \\
\text { - } \begin{array}{l}\text { Tutors related theory to practice whilst demonstrating to learners the } \\
\text { relevance of topics covered } \\
\text { - Learner support was structured around module assessment requirements } \\
\text { including formative assessments }\end{array} \\
\text { - Assessments were developed to encourage tutor 'availability' and } \\
\text { 'visibility' and were the basis of tutor/learner dialogue } \\
\text { Clear goals and standards were evident to learners such as detailed } \\
\text { assessment briefs and exemplar work } \\
\text { - Tutors appropriately structured module VLEs with resources and access } \\
\text { to further reading to act as a 'safety net' for learners }\end{array}$ \\
\hline
\end{tabular}




\begin{tabular}{|c|c|}
\hline & $\begin{array}{l}\text { - Tutors displayed self-efficacy in face-to-face environments and in } \\
\text { providing learner support. }\end{array}$ \\
\hline $\begin{array}{l}\text { Factors } \\
\text { influencing } \\
\text { learner } \\
\text { perceptions of } \\
\text { quality }\end{array}$ & $\begin{array}{l}\text { - Tutors developed strategies to manage adult's needs such as } \\
\text { consideration of spread of assessment deadlines } \\
\text { - Tutors promoted a simple module structure focussed around assessment } \\
\text { that created more 'space' for learning } \\
\text { - Tutors were clear of the purpose of adopted educational technologies, } \\
\text { which align with desired learning activities and outcomes } \\
\text { - Tutors' pedagogical beliefs aligned with the Individual Constructivist } \\
\text { Perspective } \\
\text { - Tutors perceived blended learning as an opportunity for learners } \\
\text { - Tutors displayed self-efficacy in all teaching and learning environments in } \\
\text { blended contexts. }\end{array}$ \\
\hline
\end{tabular}

There are similarities with some of Constructivism's lower level factors with those of the other Dimensions. Teaching, learning and assessment factors were firmly rooted in constructivism with the support strategies helping provide a structured learning environment. This support prompted tutor/learner dialogue with further guidance provided by an appropriately structured VLE, assessment briefs and exemplar work. The VLE, which can act as a 'safety net' should learners experience difficulties, could sit in the Care/Nurture Dimension, however, the structured support it can provide suggested a greater congruence with constructivism. Further, tutors' use of educational technologies, pedagogical beliefs, and perceptions of blended learning as an opportunity for learners, could sit within Instrumentality, but all support constructivist approaches to learning if adopted together.

Table 2 Care/Nurture Dimension's lower level factors

\begin{tabular}{|c|c|}
\hline & $\begin{array}{l}\text { Care/Nurture - factors associated with, and influencing, learner perceptions of } \\
\text { quality }\end{array}$ \\
\hline $\begin{array}{l}\text { Factors } \\
\text { associated with } \\
\text { effective practice }\end{array}$ & $\begin{array}{l}\text { - Tutors were committed to learner support } \\
\text { - Tutors motivated and encouraged learners in face-to-face environments } \\
\text { - Tutors were empathic to adult learner needs and mindful of their } \\
\text { competing pressures } \\
\text { - Tutors were enthusiastic about their subject, face-to-face delivery, and } \\
\text { learner support. }\end{array}$ \\
\hline $\begin{array}{l}\text { Factors } \\
\text { influencing } \\
\text { learner } \\
\text { perceptions of } \\
\text { quality }\end{array}$ & $\begin{array}{l}\text { - Tutors provided proactive and not reactive learner support } \\
\text { - Tutors provided proactive and not reactive communications such as } \\
\text { communication before the first day school } \\
\text { - Tutors taught learners at multiple points during courses when practical, } \\
\text { thereby encouraging relationships to develop. }\end{array}$ \\
\hline
\end{tabular}

There are similarities with some of Care/Nurture's lower level factors with the other Dimensions, particularly around notions of communication and support. Providing proactive communications and support encouraged constructivist approaches to learning, however, the thought and planning required to undertake these actions suggest a greater congruence with Care/Nurture. Tutors' adopting these strategies undertook extra activities to engage with and support learners, which demonstrated a 
commitment beyond what could be described as effective constructivist teaching. This commitment influenced the decision to add these factors to the Care/Nurture Dimension.

All the factors in the Care/Nurture Dimension are strengthened if tutors possess the group of ECs described by Youde [2], who proposed a framework of ECs that appeared to contribute to tutor effectiveness in a blended learning environment.

Table 3 Instrumentality Dimension's lower level factors

\begin{tabular}{|c|c|}
\hline & $\begin{array}{l}\text { Instrumentality - factors associated with, and influencing, learner perceptions of } \\
\text { quality }\end{array}$ \\
\hline $\begin{array}{l}\text { Factors } \\
\text { associated with } \\
\text { effective practice }\end{array}$ & $\begin{array}{l}\text { - Tutors had colleagues to collaborate with and discuss effective } \\
\text { pedagogy in blended learning contexts; } \\
\text { - Tutors had available mentors or coaches to discuss effective use of } \\
\text { educational technologies in blended learning contexts; } \\
\text { - Tutors' departments had a 'culture of support'; } \\
\text { - Tutors effectively used e-mail; } \\
\text { - Educational technologies were robust; } \\
\text { - There was available technical support; } \\
\text { - Tutors had a minimum basic level of IT skills. }\end{array}$ \\
\hline $\begin{array}{l}\text { Factors } \\
\text { influencing } \\
\text { learner } \\
\text { perceptions } \\
\text { quality }\end{array}$ & $\begin{array}{l}\text { - Tutors managed competing pressures and were organised } \\
\text { - Tutors solved problems as they occur and displayed initiative } \\
\text { - Tutors had blended learning experience or developed in practice } \\
\text { - Tutors with high IT technical skills negatively influenced learner } \\
\text { perceptions of quality. }\end{array}$ \\
\hline
\end{tabular}

There are similarities with some of Instrumentality's lower level factors with the other Dimensions, such as the effective use of e-mail, but there are tensions around notions of tutor collaboration and cultures of support. These factors suggest the development of practice within communities [14], which are constructivist in orientation. However, as these factors were not directly related to the teaching and learning within modules, they have been located in the Instrumentality Dimension. Further, and somewhat light-heartedly, tutor collaborations around effective practice could lead to behaviourist orientations being adopted throughout the modules, which would conflict with the predominant constructivist approaches. Again, some of these factors, such as tutors solving problems as they occur, are strengthened if tutors possess the group of ECs proposed by Youde [2].

\section{IMPLICATIONS FOR PRACTICE}

The Model suggests qualities and skills of effective tutors and provides a summary of effective tutoring in the context under investigation, which could support lecturers, course leaders and managers in delivering successful blended learning programmes. The Model could:

- assist tutors' teaching, assessment and learner support by, for example, structuring support around module assessment requirements

- support the recruitment and selection of tutors for this context by highlighting the importance of, for example, pedagogical beliefs aligning with the Individual Constructivist Perspective [12], specific ECs, and self-efficacy in blended learning contexts 
- support tutors' training needs analyses by, for example, highlighting and exploring unexamined assumptions, and considering effective e-mail and VLE use

- support course leaders in the development of blended learning programmes to, for example, provide a course structure that encourages tutor/learner relationships to foster, and ensure there are a mix of assessment strategies appropriate for adults studying vocationally relevant degrees

- support university managers to ensure there is, for example, robust educational technology with available technical support, and a culture of sharing and support amongst academic staff.

\section{CONCLUDING THOUGHTS}

This paper has synthesised themes from a number of sources to present a Model of the Observed Tutor Beliefs and Practices. These literatures were all from one significant, in depth study of a particular blended learning context. The Model requires further research to broaden the empirical base and needs further research both within similar university schools and across a range of subject disciplines to enhance its construct validity. The findings may have differed if a broader mix of disciplines was included in the study.

\section{REFERENCES}

[1] A. Youde, "I don't need peer-support: effective tutoring in blended learning environments for learners studying vocationally orientated degrees," INTED 2017 Proceedings: 11th International Technology, Education and Development Conference, ISBN 978-84-617-8491-2. pp. 15521561., 2017.

[2] A. Youde, "Tutor Emotional Competences Valued by Learners in a Blended Learning Context," European Journal of Open, Distance and E-Learning (EURODL), vol. 19, no. 2, pp. 81-97., 2016. ISSN 1027-5207.

[3] A. Youde, "Andragogy in blended learning contexts: effective tutoring of adult learners studying part-time, vocationally relevant degrees at a distance," International Journal of Lifelong Education, vol. 37, no. 2, pp. 255-272., 2018. doi: 10.1080/02601370.2018.1450303.

[4] A. Youde, "An Exploration of Tutor Perceptions and Practice within Blended Learning Environments". EduLearn 2018 Proceedings: 10th International Conference on Education and New Learning Technologies. ISBN 978-84-09-02709-5. pp. 403-412., 2018.

[5] A. Youde, "The effective blended tutor: supporting adult learners studying part-time, vocationally relevant degrees at a distance", INTED 2016 Proceedings: IATED. ISBN $9788460856177 . \mathrm{pp}$. 1589-1598., 2016.

[6] A. Youde, "Blended tutoring: an exploration of tutor emotional competences valued by learners in a higher education context", INTED 2015, the 9th International Technology, Education and Development Conference, 2nd - 4th March, 2015, Madrid, Spain., 2015.

[7] J. W. Creswell \& V. L. Plano Clark, "Designing and conducting mixed methods research." Sage Publications, London, 2007.

[8] P. Ramsden, "A performance indicator of teaching quality in higher education: The Course Experience Questionnaire," Studies in Higher Education, vol. 16, pp. 129-150, 1991.

[9] N. King, "Using templates in the thematic analysis of text" in Essential Guide to Qualitative Methods in Organisational Research, (C. Cassell \& G. Symon, eds.), pp. 256-271., London: Sage Publications. 2004.

[10] A. Bryman, "Social Research Methods," 3rd ed., Oxford: Oxford University Press, 2008.

[11] J. H. Stronge, "Qualities of Effective Teachers," Alexandria, USA: Association for Supervision and Curriculum Development. 2002.

[12] T. Mayes \& S. de Freitas, "Learning and e-learning: the role of theory," in Rethinking Pedagogy for a Digital Age: Designing and delivering e-learning, (H. Beetham \& R. Sharpe, eds.), pp. 1325, Abingdon, Oxfordshire: Routledge, 2007. 
[13] J. Biggs \& C. Tang, "Teaching for Quality Learning at University," $3^{\text {rd }}$ ed., Maidenhead: Open University Press. 2007.

[14] J. Lave \& E. Wenger, "Situated learning: Legitimate peripheral participation." Cambridge: Cambridge University Press, 1991. 